\title{
Brazilian version of the Self-Estimated Functional Inability because of Pain questionnaire for musculoskeletal injuries relating to dance and sport: translation and cross-cultural adaptation
}

Jodimar Ribeiro dos Reis-Júnior', Jhonata Botelho Protázio", Aila Maria Muribeca-de-Castro'"', Jocassia Silva Pinheiro'v, Henrique Yuji Takahasi ", Flavio de Oliveira Pires"', Sergio Augusto Rosa de Souzav", Cid André Fidelis-de-Paula-Gomes "III, Adriana Sousa Rêgo'x, Daniela Bassi-Dibaix , Almir Vieira Dibai-Filho ${ }^{\mathrm{XI}}$

Universidade Federal do Maranhão (UFMA), São Luís (MA), Brazil

'Undergraduate Student, Department of Physical Education, Universidade Federal do Maranhão (UFMA), São Luís (MA), Brazil. (D) orcid.org/0000-0001-9335-2504

"Undergraduate Student, Department of Physical Education, Universidade Federal do Maranhão (UFMA), São Luís (MA), Brazil. (D) orcid.org/0000-0001-8468-0434

"'Undergraduate Student, Department of Physical Education Universidade Federal do Maranhão (UFMA), São Luís (MA), Brazil. (D) orcid.org/0000-0001-8804-761X

"Undergraduate Student, Department of Physical Education, Universidade Federal do Maranhão (UFMA), São Luís (MA), Brazil. (D) orcid.org/0000-0003-4765-9024

vPT. Master's Student, Postgraduate Program on Physical Education, Universidade Federal do Maranhão (UFMA), São Luís (MA), Brazil.

(D) orcid.org/0000-0003-1603-9228

MPT. Professor, Department of Physical Education, Universidade Federal do Maranhão (UFMA), São Luís (MA), Brazil.

(D) orcid.org/0000-0002-9497-8928

viphD. Professor, Department of Physical Education,

Universidade Federal do Maranhão (UFMA), São Luís (MA), Brazil. (D) orcid.org/0000-0003-2633-9654

VIIPhD. Professor, Postgraduate Program on Rehabilitation Sciences, Universidade Nove de Julho, São Paulo (SP), Brazil. (D) orcid.org/0000-0001-6627-7537

xPhD. Professor, Postgraduate Program on Program Management and Healthcare Services, Universidade Ceuma, São Luís (MA), Brazil.

(D) orcid.org/0000-0002-2494-030X

xphD. Professor, Postgraduate Program on Program Management and Healthcare Services, Universidade Ceuma, São Luís (MA), Brazil.

(D) orcid.org/0000-0002-6140-0177

xPhD. Professor, Postgraduate Program on Physical Education, Universidade Federal do Maranhão (UFMA), São Luís (MA), Brazil.

(D) orcid.org/0000-0001-5403-8248

KEY WORDS (MeSH terms):

Pain measurement

Reproducibility of results.

Surveys and questionnaires.

AUTHORS' KEY WORDS:

Cross-cultural adaptation.

Dance injury.

Sports injury.

\begin{abstract}
BACKGROUND: Self-Estimated Functional Inability because of Pain (SEFIP) is a questionnaire specifically designed to measure musculoskeletal pain or discomfort.

OBJECTIVE: To perform translation and cross-cultural adaptation of the SEFIP for dancers (SEFIP-dance), for use in Brazilian Portuguese. In addition, as a secondary objective, we adapted the translated version of SEFIP-dance for use among athletes or exercise practitioners (SEFIP-sport).

DESIGN AND SETTING: Questionnaire translation and cross-cultural adaptation study conducted at a public university.

METHODS: The Brazilian version of the SEFIP-dance questionnaire was developed following the processes of translation (involving two translators with Brazilian Portuguese as their mother tongue and fluency in English), backtranslation (involving two translators with English as their mother tongue and fluency in Brazilian Portuguese), committee review and pre-testing. SEFIP-sport was developed following the processes of content and face validation.

RESULTS: SEFIP-dance was applied to 30 dancers, of mean age 22.38 years (standard deviation [SD] = 3.41), among whom 14 were men (46.66\%). The participants understood 100\% of the SEFIP-dance items and alternatives. SEFIP-sport was applied to 30 athletes or physical exercise practitioners, of mean age 25.09 years (SD $=8.93)$, among whom 25 were men (86.33\%). The participants understood $100 \%$ of the SEFIP-sport items and alternatives.

CONCLUSION: The Brazilian Portuguese versions of SEFIP-dance, translated and cross-culturally adapted for dancers, and SEFIP-sport, adapted for athletes or physical exercise practitioners, were shown to have adequate levels of understanding.
\end{abstract}

\section{INTRODUCTION}

Cross-cultural adaptations of questionnaires in developing countries, such as Brazil, have fostered a major debate involving the fields of economics, health, politics and culture. ${ }^{1}$ Today, with the development and dissemination of the Guidelines for the Process of Cross-Cultural Adaptation of Self-Report Measures ${ }^{2}$ and of the Consensus-based Standards for the Selection of Health Measurement Instruments (COSMIN), ${ }^{3}$ standardization of cross-cultural adaptation relating to culture, language and country is providing positive outcomes within scientific and clinical contexts.

Within healthcare sciences, especially in the field of prevention and rehabilitation of musculoskeletal injuries, it is common to use questionnaires to measure self-reported outcomes, mainly in relation to pain and functional disability. ${ }^{4-6}$ Among the questionnaires for screening of musculoskeletal injuries, in addition to instruments that were created by researchers for specific evaluations, ${ }^{7,8}$ the Nordic Musculoskeletal Questionnaire (NMQ) stands out through its widespread use for locating musculoskeletal pain in diverse populations. ${ }^{9-12}$ However, the NMQ does not have a severity score, and it is not possible to use it to make inferences about functional disability.

Therefore, as a way to fill this gap, the Self-Estimated Functional Inability because of Pain (SEFIP) questionnaire was developed and published in 1999. This is an instrument created based 
on the NMQ but with the addition of severity grades relating to functional disability. ${ }^{13}$ However, the SEFIP questionnaire was specifically designed to measure musculoskeletal pain or discomfort in dancers. It has nonetheless been used in important studies ${ }^{14,15}$ and has already been translated and validated for the Turkish language. ${ }^{16}$

However, there is no validated questionnaire in the Portuguese language to measure pain and screen for musculoskeletal injuries specifically in dancers. Thus, there is justification for such a study. In addition, since the SEFIP questionnaire has a broad and usable structure for individuals who are not involved in dance, we highlight the importance of performing adaptations for its use in other populations, such as athletes ${ }^{14}$ and exercise practitioners, ${ }^{8}$ who commonly present musculoskeletal pain.

Given the above, the primary objective of this study was to perform the translation and cross-cultural adaptation of the SEFIP questionnaire for dancers (SEFIP-dance), for use in Brazilian Portuguese. In addition, as a secondary objective, we adapted the translated version of SEFIP-dance for use among athletes or exercise practitioners (SEFIP-sport).

\section{METHODS}

\section{Study design}

This was a cross-sectional study on translation and cross-cultural adaptation of a questionnaire. It was conducted in accordance with the Guidelines for the Process of Cross-cultural Adaptation of Self-Report Measures ${ }^{2}$ and the COSMIN. ${ }^{3}$ After our institution's research ethics committee had approved the procedures for the study (through opinion number 3.051.824; date: December 3 , 2018), the study was conducted at this public university. The recruitment of participants took place in communities around the university by means of verbal disclosure, posters and social media. All participants included in the study validated their participation by signing a free and informed consent statement.

\section{Translation and cross-cultural adaptation of SEFIP-dance}

The process of translation and cross-cultural adaptation of SEFIP-dance for Brazilian Portuguese followed the criteria of Beaton et al. ${ }^{2}$ and was performed in five stages, as described below.

1) Translation: Two independent translators, comprising one physiotherapist with 10 years of experience in rehabilitation (T1) and one English teacher with 21 years of experience in translation without technical knowledge of the field of healthcare (T2), with Brazilian Portuguese as their mother tongue and fluency in English, translated the original version of SEFIP-dance into Brazilian Portuguese.

2) Synthesis of translations: After discussions and revisions, the two translators, under observation by one of the researchers, synthesized the two independently translated versions of the questionnaire (T1 and T2) and produced a single consensual version of SEFIP-dance (T12).

3) Back-translation: Two independent translators (without technical knowledge of the field of healthcare), both with English as their mother tongue and fluency in Portuguese, translated the Portuguese version of SEFIP-dance back into English, without previous knowledge of the original version of the questionnaire (B1 and B2). These translators were not the same as those in phase 1 (English to Portuguese language translation).

4) Expert committee review: Four rehabilitation experts, together with the four translators involved in the project, reviewed all the translated and back-translated versions for corrections of possible discrepancies, thus reaching the pre-final version of the rehabilitation project. At this stage, the criteria for including rehabilitation experts were as follows: time availability, fluency in both languages, clinical expertise with dancers and interest in collaborating in the study. The pre-final version of SEFIP-dance was agreed among all the committee members.

5) Pre-final test: The pre-final version of SEFIP-dance was applied to 30 dancers with pain in any body region and with Brazilian Portuguese as their mother tongue. The participants read and completed the questionnaire and, at the end of the questionnaire, established that they had understood the pre-final version of SEFIP-dance by selecting check boxes containing "yes" or "no" answers to each question on the questionnaire. If questions were not understood by more than $20 \%$ of participants, it was established that they would be reworded and retested among new samples of 30 participants each, ${ }^{17}$ until the desired level of understanding was reached, thus arriving at the final version of SEFIP-dance in Brazilian Portuguese.

\section{Sample for adaptation of SEFIP-dance}

We used the following eligibility criteria for selecting the adaptation sample: professional dancers and/or dancers who used dance as a recreational activity, with a weekly frequency of at least twice a week; with the ability to read and write in Brazilian Portuguese; without cognitive impairment; and aged 18 years or older.

\section{Adaptation for SEFIP-sport}

Initially, two researchers who were directly involved in the SEFIP-dance translation and cross-cultural adaptation process made changes to SEFIP-dance to readdress the questions and items of the questionnaire for athletes and sports practitioners (SEFIP-sport). This first version of SEFIP-sport was then submitted for face and content validation in two phases. ${ }^{18}$

First phase, two physical therapists and two physical education professionals working in the field of sports rehabilitation were consulted with regard to making technical judgments about alterations, inclusions or exclusions of items in the questionnaire and establishing 
whether the questionnaire was adequate for measuring musculoskeletal pain-related disability. The criteria for including these experts were the following: time availability, fluency in both languages, clinical and scientific expertise with sports rehabilitation and interest in collaborating in the study.

Second phase, five healthcare professionals were consulted to provide information about possible difficulties in reading the questionnaire and regarding the level of understanding of the items, clarity of response alternatives, presence of typographical errors, size of the letters, length of the questionnaire, time taken for application and overall evaluation of the questionnaire. The criteria for including these experts were the following: time availability, fluency in both languages, clinical expertise with sports rehabilitation and interest in collaborating in the study.

After the face and content validity had been established, the pre-final version of SEFIP-sport was applied to 30 regular practitioners of any sport (who had been doing this for at least 6 months), aged 18 years or older, with Brazilian Portuguese as their mother tongue. The evaluation procedures for the pre-final version of SEFIP-sport followed the same principles as used for SEFIP-dance, thus reaching the final version of SEFIP-sport.

\section{Scoring for SEFIP-dance and SEFIP-sport}

Each questionnaire consists of 14 items, each relating to one body part, and it is possible to mark one of five answers for each item, which correspond to scores from 0 to 4 . Thus, the total score ranges between 0 and 56 points. ${ }^{13}$ The higher the score is, the greater the disability also is. However, to avoid errors in interpreting the magnitude of functional disability through the total score, we suggest that separate analysis should be conducted on each body part, thus resulting in scores ranging from 0 (no pain and disability) to 4 (maximum pain and disability).

\section{Statistical analysis}

The data collected during the pre-final test phase were analyzed descriptively through presentation of quantitative variables by means of averages (with standard deviation [SD]) and categorical variables by means of absolute numbers (with percentages). Data processing was performed using the SPSS software, version 17.0 (Chicago, IL, USA).

\section{RESULTS}

\section{Translation and cross-cultural adaptation of SEFIP-dance}

The translation and back-translation processes are described in Table 1. From this process, the pre-final version of SEFIP-dance was defined by the committee of experts. This version was then applied to 30 dancers whose mother tongue was Brazilian Portuguese. The average age of the dancers was 22.38 years $(S D=3.41)$, and 14 of these participants were men (46.66\%). The most common dance

Table 1. Translation, consensus version and backtranslation of the Self-Estimated Functional Inability because of Pain (SEFIP) questionnaire for dancers

\begin{tabular}{|c|c|c|c|}
\hline SEFIP original & Translation & Consensus version & Backtranslation \\
\hline \multicolumn{4}{|l|}{ Item } \\
\hline \multirow{2}{*}{ 1. Neck } & T1: Pescoço & \multirow{2}{*}{ T12: Pescoço } & B1: Neck \\
\hline & T2: Pescoço & & B2: Neck \\
\hline 2. Shoulders & T2: Ombros & T12: Ombros & B2: Shoulders \\
\hline \multirow{2}{*}{ 3. Elbows } & T1: Cotovelos & \multirow{2}{*}{ T12: Cotovelos } & B1: Elbows \\
\hline & T2: Cotovelos & & B2: Elbows \\
\hline 4. Wrists/hands & T2: Punhos/mãos & T12: Punhos/mãos & B2: Wrists/hands \\
\hline \multirow{2}{*}{ 5. Upper back } & T1: Parte superior das costas & \multirow{2}{*}{$\begin{array}{l}\text { T12: Parte superior das } \\
\text { costas }\end{array}$} & B1: Upper back \\
\hline & T2: Parte superior das costas & & B2: Upper back \\
\hline \multirow{2}{*}{ 6. Lower back } & T1: Parte inferior das costas & \multirow{2}{*}{$\begin{array}{l}\text { T12: Parte inferior das } \\
\text { costas }\end{array}$} & B1: Lower back \\
\hline & T2: Parte inferior das costas & & B2: Lower back \\
\hline \multirow{2}{*}{ 9. Thighs (back) } & T1: Coxas (atrás) & \multirow{2}{*}{ T12: Coxas (atrás) } & B1:Thighs (back) \\
\hline & T2: Coxas (parte posterior) & & B2: Thighs (back) \\
\hline \multirow{2}{*}{ 10. Knees } & T1: Joelhos & \multirow{2}{*}{ T12: Joelhos } & B1:Knees \\
\hline & T2: Joelhos & & B2: Knees \\
\hline
\end{tabular}

Continue... 
Table 1. Continuation.

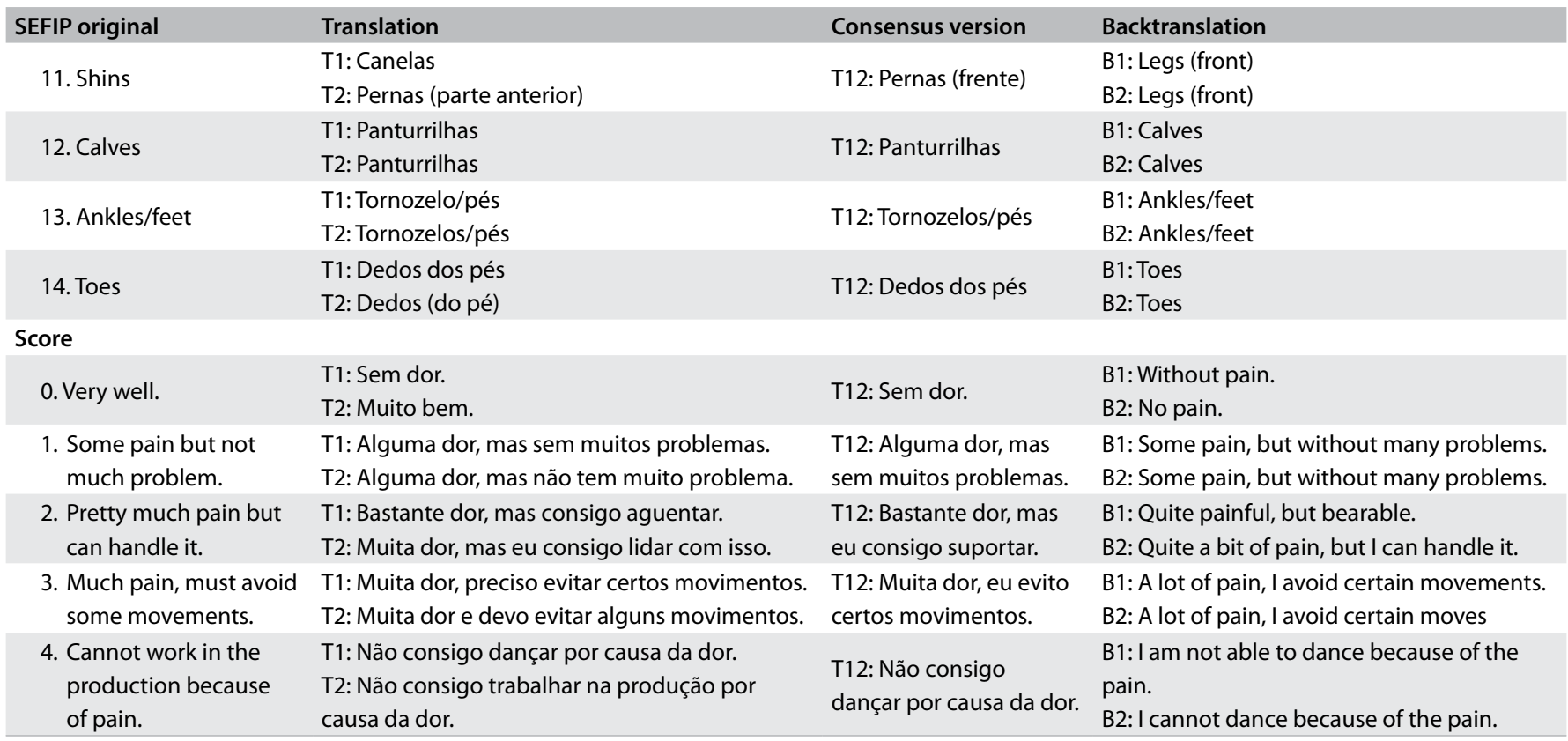

$\mathrm{T} 1=$ Translation 1; T2 = Translation 2; T12 = Consensual synthesis of translations 1 and 2; B1 = Backtranslation 1; B2 = Backtranslation 2.

styles practiced were hip-hop $(\mathrm{n}=10 ; 33.33 \%)$, jazz $(\mathrm{n}=9 ; 30 \%)$, ballroom $(n=6 ; 20 \%)$ and ballet $(n=5 ; 16.67 \%)$.

The participants understood $100 \%$ of the SEFIP-dance items and alternatives, and no changes to the pre-final version were required. The mean total score for SEFIP-dance was $5.63(\mathrm{SD}=4.66)$. The "lower back" item was the one most often marked $(n=20$; $66.66 \%)$, with a mean score of $1.06(\mathrm{SD}=0.94)$. The final version of the SEFIP-dance questionnaire in Brazilian Portuguese is presented in Appendix 1.

\section{Adaptation for SEFIP-sport}

The adaptation for SEFIP-sport was performed based on the version of SEFIP-dance that had been translated and cross-culturally adapted for the Brazilian population. Initially, the following three changes were made to the questionnaire: the alternative with score 4 was changed from "Não consigo dançar por causa da dor" ("I cannot dance because of the pain") to "Não consigo praticar o esporte por causa da dor" ("I cannot practice the sport because of the pain"); item 13 was changed from "Tornozelos/pés" ("Ankles/ feet") to "Tornozelos" ("Ankles"); and item 14 was changed from "Dedos dos pés" (“Toes") to "Pés" ("Feet"). In dance, a specific item "dedos dos pés" ("toes") is justified due to the common use of this body part, especially in styles such as ballet. However, for various sports, the term "feet" was considered broader and more accurate for SEFIP-sport. The version submitted for face and content validity was approved by $100 \%$ of the experts, with no disagreements or suggestions for changes in SEFIP-sport.
Thus, the version approved after the face and content validation was considered to be the pre-final version of SEFIP-sport. Thirty athletes or physical exercise practitioners whose mother tongue was Brazilian Portuguese answered the questionnaire. The mean age of the athletes or exercise practitioners was 25.09 years (standard deviation $[S D]=8.93$ ), and 25 of these participants were male $(86.33 \%)$. The most common sports practiced were jiu-jitsu $(\mathrm{n}=9 ; 30 \%)$, futsal $(\mathrm{n}=5 ; 16.68 \%)$, athletics $(\mathrm{n}=4 ; 13.33 \%)$, basketball $(\mathrm{n}=4 ; 13.33 \%)$, volleyball $(\mathrm{n}=4 ; 13.33 \%)$ and karate ( $\mathrm{n}=4 ; 13.33 \%)$

The participants understood $100 \%$ of the SEFIP-sport items and alternatives, and no changes to the pre-final version were required. The mean total score for SEFIP-sport was $5.07(\mathrm{SD}=4.25)$. The item "knee" was the one most often marked ( $\mathrm{n}=15 ; 50 \%)$, with a mean score of 0.70 ( $S D=0.48)$. The final version of the SEFIP-sport questionnaire in Brazilian Portuguese and English (free translation) are presented in Appendices 2 and 3.

\section{DISCUSSION}

We performed the translation and cross-cultural adaptation of SEFIP-dance for use in Brazilian Portuguese as the first step in the validation process for this questionnaire. This will allow its future use for investigating musculoskeletal injuries in dancers. In addition, because of the broad characteristics of SEFIP-dance, we were able to change and adjust the translated and adapted version of SEFIP-dance for use among athletes and exercise practitioners (SEFIP-sport). 
There are several specific questionnaires in the scientific literature that address complaints relating to certain parts of the body, such as the knee, ${ }^{19}$ hip, ${ }^{20}$ ankle and foot, ${ }^{21}$ shoulder, ${ }^{22}$ hand and wrist, ${ }^{17}$ cervical spine ${ }^{23,24}$ and lumbar spine. ${ }^{4}$ However, to assess the presence of musculoskeletal pain or discomfort throughout the body, the NMQ remains the tool most commonly used in research and clinical practice. . $^{811,12,25,26}$

The NMQ makes it possible to record which part of the subject's body has experienced pain in the last 12 months and 7 days, thus generating a nominal result. ${ }^{27}$ In a complementary manner, SEFIP-dance and SEFIP-sport not only allow recording of which body region presented pain at a given moment but also have a disability scale ranging from 0 to 4 points, thereby generating a numerical score for interpretations of pain and disability. ${ }^{13}$ Furthermore, it is noteworthy that the two questionnaires adapted here (SEFIP-dance and SEFIP-sport) are easy to understand, since $100 \%$ of the sample included in the pre-final evaluation phase understood all the questions.

This study has limitations that need to be considered. SEFIP-dance was translated and cross-culturally adapted based on Beaton et al. ${ }^{2}$ and was adapted for practitioners of any sport, based on content and face validity, ${ }^{18}$ thus creating a new questionnaire called the SEFIP-sport. Performing only cross-cultural translation and adaptation is common in the scientific literature. . $^{24,28,29}$ However, these procedures are only the first phase in properly ascertaining the validity of these questionnaires. Therefore, we recommend that further studies should be conducted to verify the psychometric properties of SEFIP-dance in Brazilian Portuguese and SEFIP-sport in Brazilian Portuguese and English.

\section{CONCLUSION}

The Brazilian Portuguese versions of SEFIP-dance, translated and cross-culturally adapted for dancers, and SEFIP-sport, adapted for athletes or physical exercise practitioners, were shown to have adequate levels of understanding in the target population for each questionnaire.

\section{REFERENCES}

1. Cruciani F, Adami F, Assunção NA, Bergamaschi DP. Equivalência conceitual, de itens e semântica do Physical Activity Checklist Interview (PACI) [Conceptual, item, and semantic equivalence of a Brazilian version of the Physical Activity Checklist Interview (PACI)]. Cad Saude Publica. 2011;27(1):19-34. PMID:21340101; doi: 10.1590/50102-311×2011000100003.

2. Beaton DE, Bombardier C, Guillemin F, Ferraz MB. Guidelines for the process of cross-cultural adaptation of self-report measures. Spine (Phila Pa 1976). 2000;25(24):3186-91. PMID: 11124735; doi: 10.1097/00007632200012150-00014.

3. Prinsen CAC, Mokkink LB, Bouter LM, et al. COSMIN guideline for systematic reviews of patient-reported outcome measures. Qual Life Res. 2018;27(5):1147-57.PMID:29435801; doi: 10.1007/s11136-018-1798-3.
4. Chiarotto A, Maxwell LJ, Terwee CB, et al. Roland-Morris Disability Questionnaire and Oswestry Disability Index: Which Has Better Measurement Properties for Measuring Physical Functioning in Nonspecific Low Back Pain? Systematic Review and Meta-Analysis. Phys Ther. 2016;96(10):1620-37. PMID: 27081203; doi: 10.2522/ptj.20150420.

5. Menezes Costa L da C, Maher CG, McAuley JH, Costa LO. Systematic review of cross-cultural adaptations of McGill Pain Questionnaire reveals a paucity of clinimetric testing. J Clin Epidemiol. 2009;62(9):934-43. PMID: 19595572; doi: 10.1016/j.jclinepi.2009.03.019.

6. Leysen M, Nijs J, Meeus M, et al. Clinimetric properties of illness perception questionnaire revised (IPQ-R) and brief illness perception questionnaire (Brief IPQ) in patients with musculoskeletal disorders: A systematic review. Man Ther. 2015;20(1):10-7. PMID: 25435470; doi: 10.1016/j.math.2014.05.001

7. Ferreira AC, Dias JMC, Fernandes R de $M$, et al. Prevalência e fatores associados a lesões em corredores amadores de rua do município de Belo Horizonte, MG. Rev Bras Med Esporte. 2012;18(4):252-5. doi: 10.1590/S1517-86922012000400007.

8. Meurer MC, Silva MF, Baroni BM. Strategies for injury prevention in Brazilian football: Perceptions of physiotherapists and practices of premier league teams. Phys Ther Sport. 2017;28:1-8. PMID: 28886473; doi: 10.1016/j.ptsp.2017.07.004.

9. Bleyer FTS, Barbosa DG, Andrade RD, et al. Sleep and musculoskeletal complaints among elite athletes of Santa Catarina. Rev Dor. 2015;16(2):102-8. doi: 10.5935/1806-0013.20150020.

10. Falcão IR, Rêgo RCF, Couto MCBM, et al. Fatores associados com os distúrbios musculoesqueléticos em pescadoras artesanais/marisqueiras em Saubara, Bahia, Brasil [Factors associated with musculoskeletal disorders in artisanal fishermen/shellfish gatherers in Saubara, Bahia, Brazil]. Cien Saude Colet. 2019;24(7):2557-68. doi: 10.1590/141381232018247.19712017

11. Morais BX, Dalmolin GL, Andolhe R, Dullius AIDS, Rocha LP. Musculoskeletal pain in undergraduate health students: prevalence and associated factors. Rev Esc Enferm USP. 2019;53:e03444. PMID: 31314863; doi: 10.1590/S1980-220X2018014403444.

12. Cabral AM, Moreira RFC, de Barros FC, Sato TO. Is physical capacity associated with the occurrence of musculoskeletal symptoms among office workers? A cross-sectional study. Int Arch Occup Environ Health. 2019;92(8):1159-72. PMID: 31273500; doi: 10.1007/s00420-019-01455-y.

13. Ramel EM, Moritz U, Jarnlo GB. Validation of a pain questionnaire (SEFIP) for dancers with a specially created test battery. Med Probl Perform Art. 1999;14(4):196-203.

14. Jacobs CL, Cassidy JD, Côté P, et al. Musculoskeletal Injury in Professional Dancers. Prevalence and Associated Factors: An International CrossSectional Study. Clin J Sport Med. 2017;27(2):153-60. PMID: 26889817; doi: 10.1097/JSM.0000000000000314

15. Miletic A, Kostic R, Miletic D. Pain Prevalence among Competitive International Dancers. Int J AthlTher Train. 2011;16(1):13-6. doi: 10.1123/ ijatt.16.1.13. 
16. Yurt Y, YakutY, Sener G. AB1106 Validity and reliability of Turkish version of self-estimated functional inability because of pain (SEFIP) questionnaire and determination of pain profile in a Turkish folk dancer group. Ann Rheum Dis. 2013;71(Suppl 3):701. doi: 10.1136/annrheumdis-2012-eular.1104.

17. da Silva Rodrigues EK, de Cássia Registro Fonseca M, MacDermid JC. Brazilian version of the Patient Rated Wrist Evaluation (PRWE-BR): Cross-cultural adaptation, internal consistency, test-retest reliability and construct validity. J Hand Ther. 2015;28(1):69-76. PMID: 25446520; doi: 10.1016/j.jht.2014.09.008.

18. De Groef A, Van Kampen M, Moortgat P, et al. An evaluation tool for Myofascial Adhesions in Patients after Breast Cancer (MAP-BC evaluation tool): Concurrent, face and content validity. PLoS One. 2018;13(3):e0193915. PMID: 29522540; doi: 10.1371/journal. pone.0193915.

19. Esculier JF, Roy JS, Bouyer LJ. Psychometric evidence of self-reported questionnaires for patellofemoral pain syndrome: a systematic review. Disabil Rehabil. 2013;35(26):2181-90. PMID: 23627531; doi: 10.3109/09638288.2013.774061.

20. Peter WF, deVet HCW, Boers M, et al. Cross-Cultural and Construct Validity of the Animated Activity Questionnaire. Arthritis Care Res (Hoboken). 2017;69(9):1349-59. PMID: 27748072; doi: 10.1002/acr.23127.

21. Sierevelt IN, Zwiers R, Schats W, et al. Measurement properties of the most commonly used Foot- and Ankle-Specific Questionnaires: the FFI, FAOS and FAAM. A systematic review. Knee Surgery Sports Traumatol Arthrosc. 2018;26(7):2059-73. PMID: 29026933; doi: 10.1007/s00167-017-4748-7.

22. Martins J, Napoles BV, Hoffman CB, Oliveira AS. The Brazilian version of Shoulder Pain and Disability Index: translation, cultural adaptation and reliability. Rev Bras Fisioter. 2010;14(6):527-36. PMID: 21340248.

23. Cook C, Richardson JK, Braga L, et al. Cross-cultural adaptation and validation of the Brazilian Portuguese version of the Neck Disability Index and Neck Pain and Disability Scale. Spine (Phila Pa 1976). 2006;31(14):1621-7. PMID: 16778699; doi: 10.1097/01. brs.0000221989.53069.16

24. Badaró FAR, Araújo RC, Behlau M. The Copenhagen Neck Functional disability scale - CNFDS: translation and cultural adaptation to Brazilian Portuguese. J Hum Growth Dev. 2014;24(3):304-12. doi: 10.7322/jhgd.88965.

25. Scarabottolo CC, Pinto RZ, Oliveira CB, et al. Back and neck pain prevalence and their association with physical inactivity domains in adolescents. Eur Spine J. 2017;26(9):2274-80. PMID: 28536945; doi: 10.1007/s00586-017-5144-1.

26. Genebra CVDS, Maciel NM, Bento TPF, Simeão SFAP, Vitta A. Prevalence and factors associated with neck pain: a population-based study. Braz J Phys Ther. 2017;21(4):274-80. PMID: 28602744; doi: 10.1016/j. bjpt.2017.05.005.

27. Pinheiro FA, Troccoli BT, Carvalho CV. Validação do Questionário Nórdico de Sintomas Osteomusculares como medida de morbidade [Validity of the Nordic Musculoskeletal Questionnaire as morbidity measurement tool]. Rev Saude Publica. 2002;36(3):307-12. PMID: 12131969; doi: 10.1590/s0034-89102002000300008.
28. Kamonseki DH, Fonseca CL, Calixtre LB. The Brazilian version of the Bournemouth questionnaire for low back pain: translation and cultural adaptation. Sao Paulo Med J. 2019. pii: S1516-31802019005004102. doi: 10.1590/1516-3180.2018.0482120419.

29. Delfino LL, Komatsu RS, Komatsu C, Neri AL, Cachioni M. Brazilian transcultural adaptation of an instrument on communicative strategies of caregivers of elderly with dementia. Dement Neuropsychol. 2017;11(3):2428. PMID: 29213520; doi: 10.1590/1980-57642016dn11-030005.

Authors' contributions: Reis-Júnior Jr and Protázio JB: conceptualization (Equal), data curation (Equal), methodology (Equal), and writing-original draft (Equal); Muribeca-de-Castro AM: conceptualization (Equal), data curation (Equal), formal analysis (Equal), methodology (Equal), and writing-original draft (Equal); Pinheiro JS: conceptualization (Equal), formal analysis (Equal), methodology (Equal), and writing-original draft (Equal); Takahasi HY, Pires FO and Rêgo AS: methodology (Equal), supervision (Equal), writing-review \& editing (Equal); Souza SAR: conceptualization (Equal), data curation (Equal), formal analysis (Equal); methodology (Equal), and writing-review \& editing (Equal); Fidelis-de-Paula-Gomes CA and Bassi-Dibai D: conceptualization (Equal), formal analysis (Equal), methodology (Equal), and writing-review \& editing (Equal); Dibai-Filho AV: Conceptualization (Equal), Data curation (Equal), Funding acquisition (Equal), Methodology (Equal), Project administration (Equal), Writing-review \& editing (Equal). All authors approved the final version for publication

Sources of funding: Undergraduate students were supported by Programa Institucional de Bolsas de Iniciação Científica e Tecnológica/ Conselho Nacional de Desenvolvimento Cientifico e Tecnológico (PIBIC) CNPq and PIBITI/CNPq, grants PICBS993-2017 and PVCBS1559-2019) and Programa Institucional de Bolsas de Iniciação Científica/Fundação de Amparo à Pesquisa e ao Desenvolvimento Científico e Tecnológico do Maranhão (PIBIC/FAPEMA, grant BIC-04307/19)

\section{Conflict of interest: None}

Date of first submission: August 28, 2019

Last received: October 5, 2019

Accepted: October 8, 2019

\section{Address for correspondence:}

Almir Vieira Dibai-Filho

Departamento de Educação Física, Centro de Ciências Biológicas e da Saúde, Universidade Federal do Maranhão (UFMA)

Av. dos Portugueses, 1.966

Vila Bacanga — São Luís (MA) - Brasil

CEP 65080-805

Tel. (+55 98)3272-9063

E-mail: dibaifilho@gmail.com 
Appendix 1. Brazilian Portuguese version of the Self-Estimated Functional Inability because of Pain questionnaire for dancers (SEFIP-dance).

\section{Self-Estimated Functional Inability because of Pain}

(Dança)

Nome:

Data:

Você está sentindo qualquer dor ou desconforto muscular agora? Se sim, indique abaixo até que ponto isso afeta sua dança.

Por favor, marque um quadrado para cada região do corpo.

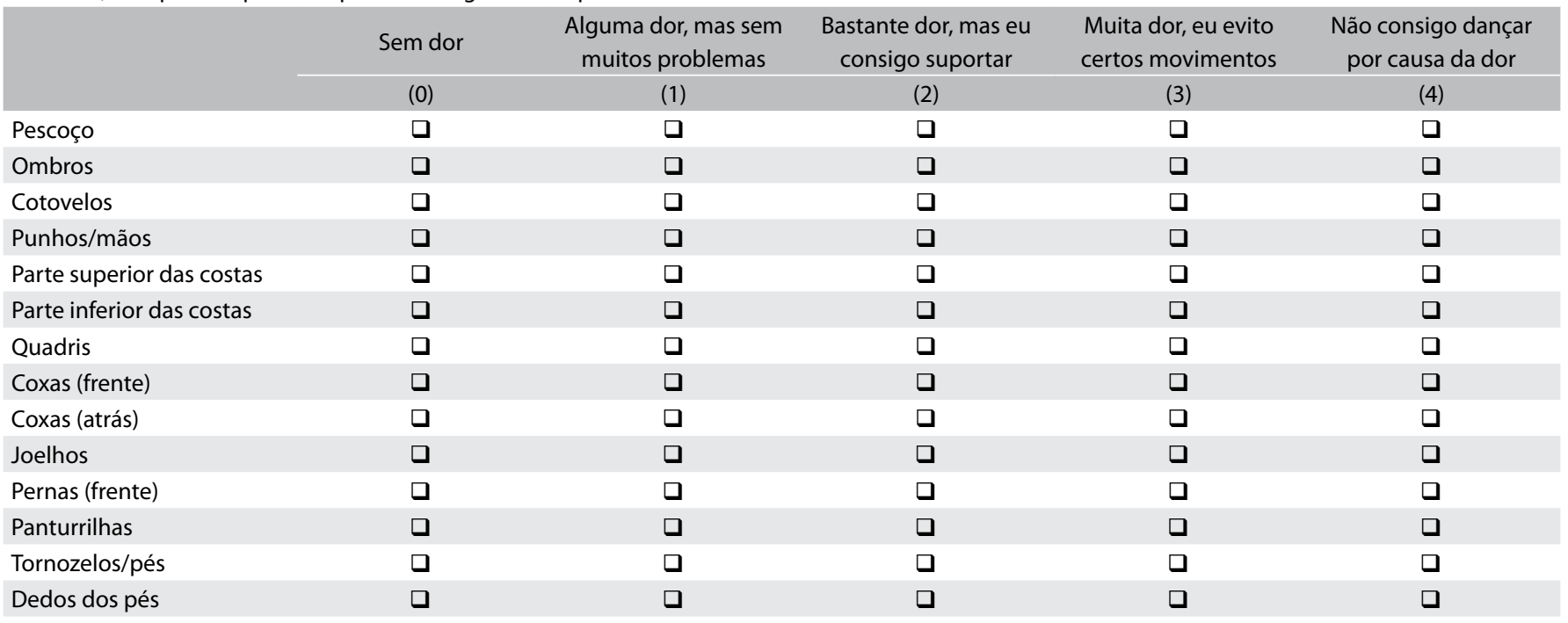

Appendix 2. Brazilian Portuguese version of the Self-Estimated Functional Inability because of Pain questionnaire for athletes or exercise practitioners (SEFIP-sport).

\section{Self-Estimated Functional Inability because of Pain}

(Esporte)

Nome:

Data:

Você está sentindo qualquer dor ou desconforto muscular agora? Se sim, indique abaixo até que ponto isso afeta sua prática esportiva.

Por favor, marque um quadrado para cada região do corpo.

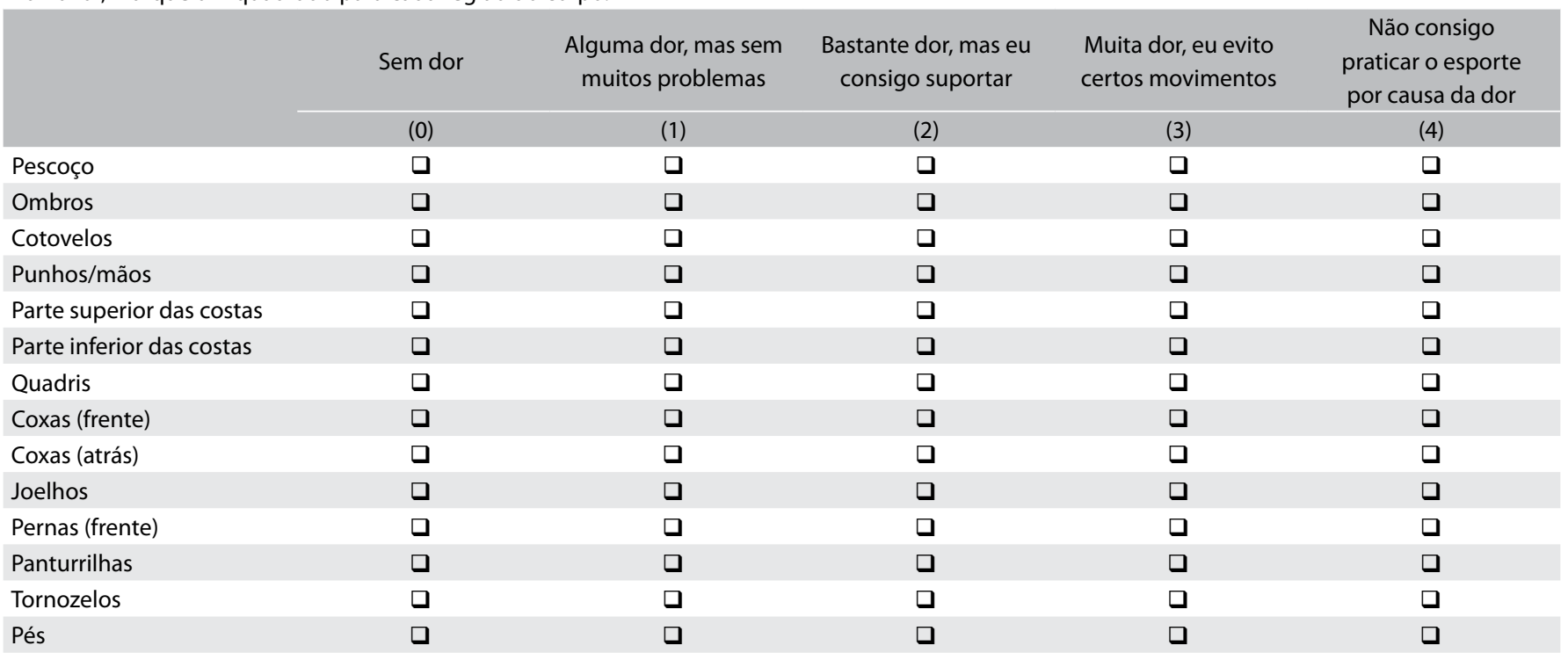


Appendix 3. English version (free translation) of the Self-Estimated Functional Inability because of Pain questionnaire for athletes or exercise practitioners (SEFIP-sport).

\section{Self-Estimated Functional Inability because of Pain \\ (Sport)}

Nome: Data:

Are you feeling any muscle pain or discomfort now? If so, indicate below how much it affects your sports practice.

Please check one box for each body region.

\begin{tabular}{|c|c|c|c|c|c|}
\hline & No pain & $\begin{array}{l}\text { Some pain, but } \\
\text { without many } \\
\text { problems }\end{array}$ & $\begin{array}{l}\text { Quite a bit of pain, but } \\
\text { I can handle it }\end{array}$ & $\begin{array}{l}\text { A lot of pain, I avoid } \\
\text { certain moves }\end{array}$ & $\begin{array}{l}\text { I cannot practice } \\
\text { the sport because } \\
\text { of the pain }\end{array}$ \\
\hline & (0) & $(1)$ & (2) & (3) & (4) \\
\hline Shoulders & $\square$ & $\square$ & $\square$ & $\square$ & $\square$ \\
\hline Elbows & $\square$ & $\square$ & $\square$ & $\square$ & $\square$ \\
\hline Lower back & $\square$ & $\square$ & $\square$ & $\square$ & $\square$ \\
\hline Hips & $\square$ & $\square$ & $\square$ & $\square$ & $\square$ \\
\hline Thighs (front) & $\square$ & $\square$ & $\square$ & $\square$ & $\square$ \\
\hline Thighs (back) & 口 & $\square$ & $\square$ & 口 & 口 \\
\hline Knees & 口 & $\square$ & $\square$ & $\square$ & $\square$ \\
\hline Feet & $\square$ & $\square$ & $\square$ & $\square$ & $\square$ \\
\hline
\end{tabular}

